\title{
Addressing "Gender" in Gender Based Violence: A Qualitative Study of Gender Transformative Approach among Tribal's in Jharkhand
}

\author{
Vipul Vaibhav Pandey and S K Singh*
}

*Department of Mathematical Demography and Statistics, International Institute for Population Sciences, India

*Corresponding author: Singh SK, Department of Mathematical Demography and Statistics, International Institute for Population Sciences, India, Tel: +022-42372415; E-mail: sksingh@iips.net

\begin{abstract}
This is a case study of gender based violence among the different area of Jharkhand addressing the gender. It elaborates the common phenomenon of male violence and women empowerment in all societies and all social groups and classes. The experiences from field study are juxtaposed with a growing number of innovative violence against women program targeting men in the role of perpetuators.
\end{abstract}

Keywords: Gender based violence; Violence; Gender transformation; Anthropologists

Received Date: March 19, 2018; Accepted Date: May 17, 2018; Published Date: May 23, 201

\section{Introduction}

It is well established that Gender Based Violence (GBV) has remained long term practice, veiled in secrecy. This widespread phenomenon is common to all societies and is not limited to any particular social group or class. World-wide research and reports have shown, however, that to empower women, especially the poorest, it is critical to work with and through men as well. Discussing violence, against women, men are overwhelmingly found in the role of the perpetrators. Male violence is used to produce and reproduce the subordination of women, and patriarchal norms and practices create the conditions that condone and even encourage violence against women. Tackling violence is an essential component of any effort that seeks to create greater gender equality. Men can be gender sensitized in a positive way as allies with women in achieving equality. They can be seen as other than perpetrators of gender discrimination and inequity. Involving men in ending any act of violence is crucial to stop violence before it occurs. Gender transformation among men in conversations about and action against aspects of dominant traditional masculine culture, which is a societal factor contributing to partner violence. Transforming men is central to empowering by standers and primary prevention efforts where everyone is an ally and takes responsibility for ending violence. Transforming "men's attitude" as part of the solution to gender inequity is a paradigm shift that needs to be bring into the discourse on addressing issues of violence against women, and enhancing the rights of women and girls. The belief being that gender issues have to be owned and solved by the men and community together rather than the past approach of onus only on the "women as the victim". 
www.tridhascholars.org | July-2018

To elucidate the issue, first research question arguably centered the discussion is- Are tribal women really empowered? In tribal system of social organization where there is no distinct categories of dominant groups and subordinate groups- it becomes relevant to investigate the nature of these tribes more clearly in the course of exploring the major constructs of gender role attitude among tribal people. In addition, it is observed by scholars that in the post-Independence era tribal society has witnessed an unprecedented change, where women do not enjoy better social status than their counterparts in the larger Indian society. It is suggested by Basu, that increasing tendency towards growing inequality in gender relations among indigenous societies of India, are more pronounced in tribes that have integrated with mainstream Indian society. The Socio-cultural and demographic behavior including gender role attitude and violence against women of India's tribal population, which together numbered are $104,122,516$ at India's 2011 Census, or 8.6 percent of India's total population, remains one of the country's great demographic unknowns. Since, British times the study of the tribal populations has been left largely to anthropologists, who have concentrated on the behavior of individual tribes, ignoring broader demographic and health issues, and lacking the interest or necessary expertise in demographic methods that would have allowed more extensive enquiries of gender transformation among young men.

Drawing upon a robust and rich body of research on inter-cultural communication and gender development research, the study examines the structural and interpersonal dimensions of Tribal man in promoting gender equality as "violence against women" reduction strategy in tribal peopled Jharkhand State. Jharkhand has the worst known figures for gender-based violence for a state in India, with at least one in three Jharkhand women being physically or sexually assaulted in their lifetime. Data from various studies confirm the existence of gender inequalities and strain. NFHS 3, Jharkhand State report (2005-2006), clearly demonstrates that 55 percent of women from Scheduled Tribe (ST) agree that "husband is justified in hitting or beating his wife" against 50 percent women of other caste group. Evidences from NFHS 2 (1998-1999) show that women from Schedule Tribes (STs) and Lowe caste group are significantly more likely to experience domestic violence than their counterparts. Results from NFHS 3 (2005-2006) portrays that 50 percent of tribal women in Jharkhand have ever experienced any form of violence against 34 percent women coming from other caste group.

Estimates derived from a study conducted by IIPS, Mumbai and JHSPH, Baltimore (2005) in four states of India founds that, among all four states the highest prevalence of domestic violence was observed in Jharkhand, where one in three women reported having experience of domestic violence (33 percent). The study further reveals that 53 percent of women in Jharkhand responded life time ever experience of physical threats or violence. In an attempt to address masculine domination and support men to examine and transform distorted masculinities, there is a growing body of work concerning involvement of men in reproductive health, gender based violence with thirty percent of women reported experience of sexual violence in form of forced sex from their partners whereas 18 percent of women witnessed violence during pregnancy. Wife refusing husband sex was mentioned as a factor in violence by 19 percent of women. Similarly, alcohol consumption by husband appears to be an important precipitating factor for intimate partner violence (31 percent).

\section{The Research Approach}

Gender-based violence (GBV) and especially violence against women has gained international recognition as a grave social and human rights concern affecting virtually all societies. Progress in addressing GBV can be attributed in large part to groundbreaking studies this thesis explores the gender equality and gender based violence among Tribal's in Jharkhand India. 
www.tridhascholars.org | July-2018

Using a qualitative research design, the study examines the Gender transformative approach among tribal men. The study provides an ethnographic perspective of the researcher's work as how Tribal men perceive gender equality, and learn what they think of the domestic and intimate partner violence in their community and neighborhood. Focusing through transformative approach, this paper then explores how socio-cultural processes construct societal patterns of masculine domination and related individual masculine identities, and examines the use of gender transformations towards the reconstruction of new, more equitable gender identities. Data collected through focus groups and in-depth interviews. The research aims to address the major construct subjected to gender based violence and women as victim of violence.

In order to address the problem of domestic violence and to promote gender-equitable, non-violent attitudes among young men from a strategic and evidence based perspective it is necessary to have a broad understanding of the issue, particularly the extent of domestic violence and various context in which it perpetuate taking into account the nature of the target population. In developing scientific research it is important to envisage the contemporary situation of the study population. Therefore, the purpose of this research is two-fold: First to know more about a significant but deprived section of the population, especially their psycho-social and cultural constructs of gender role attitudes and how the norms coupled to gender role has transformed across generation. More broadly, such knowledge would also help to illuminate more general aspects of gender based violence, particularly the role of socio cultural and traditional values allied to it.

This study presents qualitative evidence from nine villages in central and eastern Jharkhand drawn from open-ended interviews with 10 women's life history narratives. 4 group discussions (2 with young men age 18-29, 2 with old parents age 30 and above).

\section{Lesson Learned}

While response from IDIs includes supporting the victims, ensuring the safety of the young women experiencing the abuse; and holding the perpetrator accountable through criminal prosecutions, public inquiries, compensation programs, civil actions, community-based settlements or customary legal systems. Response systems are made up of coping mechanisms that enable victims to thrive, for example referral systems in which victims are directed to the services they need, such as emotional support and counseling, medical treatment and services, and legal aid for victims and their families. Response systems encompass reporting procedures, health care, psychosocial assistance, security and safety and social support system (formal and traditional).

The qualitative data illustrated women's perception about men's controlling behavior and dimensions of the problem. But the data also brought out their concern for women's and girls' safety and the role restrictions played in protecting them, albeit in a gender inequitable way and magnitude of the phenomenon.

\section{According to one women}

"Women in Santhal community (Tribal clan) have to take permission in each and every issue of life doing without the consent of husband is not considered a good behavior in our clan. It is the practice what we can do.”

-Women, age 32, Santhal Pargana, Jharkhand

Another woman depicted her personal narrative of violence answering open ended question.

"Men used to show their possession over their wife's that is the reason why they always check our mobility. My husband does 
www.tridhascholars.org | July-2018

nothing except drinking Handi (Rice Beer) whole day and gossiping. When I come home from field I have to give explanation why I am late by few minutes.”

-Women, age 29, Dumka, Jharkhand

\section{Another women Noted}

"I and my husband used to work at same construction site we both get same amount of money on daily basis, the things were soothing till then when his portion of work got over and he became jobless. Later he started to ask money for alcohol and pangutkha, sometimes I give him money because I love him but he started to ask money every now and then, I was the only working member in the house and I have two girls. When I stopped giving him money he started to abuse me and beat me and it continued until he got another work."

-Women, age 30, Jama, Jharkhand

Other women from same village described her episode of violence

“Every day I didn't want to have sex with my husband but he usually do it by force. When he came home drunk he would beat me, and do what he wanted with me. Then I fought with him and in return he beat me more, Men are stronger than women, I couldn't do anything, so I had to live with it and bear. He used to yell on me, "If you want you leave the house and go wherever you want". I have no place to go; my father will not accept me at home. That made me feels even more worthless. I couldn't raise my voice. I think I have nothing to do in this world, and I have always been in stress ...I would think, could it be that I should die? But I don't I have a kid, I have to groom him.

-Women, age 28, Jama, Jharkhand

Similarly a 40-year-old female spoke of physical abuse as "More than half and of couples experience domestic violence. This is happening every day. I will say it's common in people of our age because you find that they show what they're doing and learning outside. They show their abuse. As with parents they don't show. They do it inside the house. No one sees it. But in people our age, it's done in every kutumb (family). I realized that my husband abuse me everywhere.”

A 34-year-old female, specifically spoke about physical intimate partner violence.

"My husband is shame to my family. He does nothing and every time he is in house sleeping and shouting on others. I and my In-Law work in others farm. One day we had to stay in field for long so we could not inform him. When I came he beat me with iron bucket. I could not work for several days. My whole body had cuts. I had to live in house workless for long time. I had no money to spend. He beat me for no reason. I live waiting for next episode of violence. He don't promise me to work or become good husband."

Another 26 -year-old female narrated.

"When my husband beat me, my son would be around. Then he would throw him in his temper, it hurt me more when he shove him than he beat me. Once, when I was returning from Gudri Hatiya (Local Market) My son was on my lap. There was no food at home, my husband got annoyed he had beaten me and he had left my eyes swollen and black, He threw my son from my lap he fell and also got severely hurt. I cried a lot, it hurts me so much. It wasn't so much the blows I had, but what really hurt me was his sobbing and the pain he was feeling. It made me feel that me I was hurting my son by staying in a marriage with no future." 
www.tridhascholars.org | July-2018

Most female participants felt that spousal violence was a common phenomenon in the community of Santhal Pargana, claiming that spousal is "very common." Santhali women felt that it was particularly common for men to abuse their intimate partners physically. This was especially the case for what most women referred to very causally as "Ha marta hai" (yes he beat me). Sexual violence causing substantial bodily harm, however, was seen to be less common. Not only does this show that santhali women perceived that some forms of gender based violence were common in the community, but it also shows how such occurrences are treated very casually, at least as seen by these participants. It is interesting that most women drew a distinction between different levels of violence, noting both the difference in occurrence and the difference in community reaction between "casual beating" and "forced sex." Because most women presents some amount of physical violence as normal phenomenon widely prevailed in community, their comments suggest that the gender differentials underlying this partner violence are generally accepted. However, different magnitude of physical, sexual and emotional violence may be differentially categorized and commonly accepted, it implies an acceptance of male as custodian of society and gender power dynamics.

Qualitative findings drawn from Focus group discussion demonstrate low awareness about Gender based violence. Four sets of focus group discussion (FGD) were conducted with young married tribal men and old male parents or guardians. Before each FGD session, the facilitators introduced themselves, explained the purpose for the visit and asked permission to take notes and use a voice recorder. Participants were assured confidentiality. The FGD had three common areas. First, researcher explored the participants' perceptions of a safe and welcoming neighborhood and whether they thought that their neighborhood fit this perspective. Second, they assessed participants' understanding of community-related gender-based violence. In particular, facilitators asked participants to talk about the different types of GBV in their neighborhood and in the homes, the factors that contributed to GBV, and the impact of GBV on survivors. Third, they explored participants' perceptions about the response systems and their awareness of existing regulations related to GBV. Also, specific topics were included to accommodate group differences. For example, old men were asked to reflect on the current scenario and its response to GBV and the roles and responsibilities of the community in dealing with GBV issues. While young men were asked for their perceptions on life skills as gender sensitive group and how they thought it helped them to respond to GBV. Additional questions explored the issue of, knowledge and attitude towards government policy towards violence against women, dowry and property rights, child hood witness to any act of violence, Action performed to stop such violence, corporal punishment etc.

During the interviews and focus group discussions the men noted that they had become more understanding of women's and girls' vulnerability to violence.

In response to the questing of whether abuse is a part of most relationships, a 21-year-old male, said, "Believe me, oh yes," Although participants of FGD acknowledged that the GBV is more widespread among segments of the poor, it was widely believed by many community members that GBV is a minor offence or "family matter" that can be easily dealt with. Many families withhold information on domestic violence related cases with the intent to protect the family name. Similar views were held by old participants and members of the community who observed that deeply-rooted family values and to protect family name don't discuss the act of family violence openly.

\section{A 50-year-old male, corroborated}

"I think it (GBV) is much family matter. If we can talk it in open then it would be better. People will respect women. Most of this violence occurs at home. It's by people who know you within the families, so when it is taking place within the family, 
www.tridhascholars.org | July-2018

these are the same people who are supposed to live with you for entire life. Do you want to expose that your father-in-law or your Husband has beaten you (women in family)? So most of them take place within the family. Even if it is known, it is discussed within the family and that matter is closed (school teacher)."

Another man from same group added

"The gender violence voucher is a bit complicated because not many wives (married females) will come in and say I was sexually abused because of the stigma. I think also there is fear to go to health facility if something serious happens. Fear of being known that she had been sexually abused or something like that, so she keeps it to herself and can't tell anybody. So you find these cases are not reported and they can't go police and ask for help (FGD, participant)."

Discussions with participants also revealed community members' perceptions that those young men who work outside are more disrespectful to the women in community and. There is evidence in the narratives that community members who work outside are discourteous to their family members and wives. As one young participants age 25 explained:

"I believe it is not (GBV) with the Santhal man who live and involved in farm (agriculture) in the community. I run shop based in the community, people often come, sit and discuss in my shop about changing behavior of young Santhal in our villages. I know that the locals believe those who went outside to work and earn drink more English beer, whisky and are more rude to their family they treat their poor family members ill-mannered and often beat their wives. I think maybe they go to the college or work place and expect their wives to live like that (FGD participant)."

To address some of the barriers to GBVR services mentioned, voucher distributors and the VMA field managers recommended that community sensitizations be intensified by working closely with local authorities and administration to create general awareness of the GBVR services vouchers and information on where to obtain services. Additionally, voucher distributors felt that they should be allowed to hand out GBVR services vouchers in the community to dispel the belief that they are for sale.

\section{According to a men}

"Earlier we use to hear the stories in our district about taunt (Teasing), Balatkar (Rape) and use to think that the girl did something to provoke. But now I recognize the soreness and trying to understand how to change the min set of the young boys in our community regarding violence which is so very important in Santhal".

-Men, age 26, Jharkhand

\section{Key Findings}

Based on the most common responses from young man and community members, the concept of gender-based violence is not clearly understood. Many of those in the study emphasized general ill treatment-physical abuse, punishment or denial of rightswithout any specific mention of gender dynamics. While educated community people, and Government employees in particular, had a clearer understanding of the concept of gender and gender-based violence, many concentrated on physical or sexual violence, without recognizing the different forms of psychological violence such as emotional or verbal abuse.

Focus group discussions revealed that adolescent girls are victims and men are perpetrators of gender-based violence. Incidents of violence occur in the neighborhood, community, and on the way to and from local hatt (Village market). The main perpetrators of gender-based violence in neighborhood are boys, with certain groups of community members responsible for 
www.tridhascholars.org | July-2018

abuses that occur while girls travel to and from hatt.

The most common pathway for reporting abuse at the community level is for the victim or observer to report to Mukhiya (usually a Village Head Man who has been elected by local Panchyat), traditional leader or takes the matter directly to Police. Each community has its own criteria for deciding when a matter is to be handled by specific authorities. It should be noted that all communities in this study agreed that a substantial number of GBV cases were not reported. There are several actions taken against perpetrators of GBV. When the offense is grave, such as having a sexual violence with a woman outside marriage, the Mukhiya is asked to transfer the perpetrators to another clan. However, evidence from the study indicates that transferring perpetrators does not solve the problem because the perpetrators often continue their behavior at the new clan (There are all together 12 different clan found in state).

\section{Conclusion and Recommendations}

Although this study reveals a lack of knowledge about gender-based violence in communities in tribe dominated Jharkhand state of India, all of the villages in the study have some kind of reporting structure in place in the event that violence against women occurs. Increased gender sensitization about women's rights in addition to cataloguing possible sanctions that can be imposed on perpetrators is a possible entry point for reducing GBV in the communities. Introducing guidance and counseling services at the community level for both perpetrators and victims of violence might also help to reduce the incidence of abuse in neighborhood. Properly addressing GBV requires interventions that tackle both the gender transformative approach among young men and the home life by soliciting support and understanding of the wider community

The experiences from field study are juxtaposed with a growing number of innovative violence against women program targeting men in the role of perpetuators. The findings strongly suggest that GBV is mounting in these villages as gender roles still intact in the hands of strong patriarch norms. Periodic surveys are recommended to measure trends in the incidence of GBV in settings where gender transformation among young men are under way and women roles must expand and they gain a stronger sense of their rights. In order to avoid social pressure to revert to default tribal gender norms, the study suggests adopting an 'intact neighborhood' approach to transforming societal gender systems into more equitable models.

\section{References}

1. International Institute for Population Sciences (IIPS) and Macro International (1999) National Family Health Survey (NFHS-2), 1998-99. India. Mumbai: IIPS.

2. International Institute for Population Sciences (IIPS) and Macro International (2007) National Family Health Survey (NFHS-3), 2005-06: Jharkhand. Mumbai: IIPS.

3. International Institute for Population Sciences (IIPS) and Macro International (2007) National Family Health Survey (NFHS-3), 2005-06: India. Mumbai IIPS.

4. International Institute for Population Sciences (IIPS) and Pop Council (2009) Youth in India; Situation and Needs 2006-07: Jharkhand. Mumbai: IIPS. 